\title{
Morphological biosignatures within aragonite from magnesium carbonate environments analogous to Jezero Crater, Mars
}

\author{
TEANNA M BURNIE ${ }^{1}$, IAN M. POWER ${ }^{1}$, CARLOS \\ PAULO $^{1}$, HÜLYA ALÇIÇEK ${ }^{2}$ AND LUISA I FALCON ${ }^{3}$ \\ ${ }^{1}$ Trent University \\ ${ }^{2}$ Pamukkale University \\ ${ }^{3}$ Universidad Nacional Autónoma de Mexico \\ Presenting Author: teannaburnie@trentu.ca
}

Jezero Crater, the landing site for NASA's Mars 2020 Perseverance Rover mission, is a paleolacustrine environment where orbital detections identified magnesium carbonates amongst ultramafic sediments and rock [1]. On Earth, lacustrine carbonates often contain biosignatures, making those at Jezero Crater ideal targets for a future return mission. Although less abundant, aragonite $\left(\mathrm{CaCO}_{3}\right)$ is commonly found in magnesium carbonate systems on Earth that are analogous to Jezero Crater and may be a better medium for preservation of morphologic biosignatures. This study examined samples from four magnesium carbonate environments that can be considered terrestrial analogues: playas near Atlin, British Columbia, Canada [2], a historic asbestos mine at Clinton Creek, Yukon, Canada [3], and lacustrine environments including Lake Salda, Turkey [4], and Lake Alchichica, Mexico [5]. X-ray diffraction data showed that some samples were predominantly composed of aragonite (Atlin and Clinton Creek), whereas others (Salda and Alchichica) were mixtures of aragonite and hydromagnesite $\left[\mathrm{Mg}_{5}\left(\mathrm{CO}_{3}\right)_{4}(\mathrm{OH})_{2} \cdot 4 \mathrm{H}_{2} \mathrm{O}\right]$. Despite waters at the field sites being saturated with respect to magnesite $\left(\mathrm{MgCO}_{3}\right)$, this mineral was either absent or present in only trace abundances, likely owing to its sluggish precipitation rates. Electron microscopy of polished and acid-etched samples revealed cell-like features similar to algae and cyanobacteria, diatom frustules, and organics resembling extracellular polymeric substances within most aragonite samples. Raman spectra were also suggestive of organic carbon in some samples. Conversely, these features were not observed in the hydromagnesite, supporting the hypothesis that aragonite is a better preservation medium for biosignatures in magnesium carbonate environments. Furthermore, laboratory experiments involving the synthesis of nesquehonite $\left(\mathrm{MgCO}_{3} \cdot 3 \mathrm{H}_{2} \mathrm{O}\right)$ in the presence of cyanobacteria indicated that mineral transformations amongst hydrated $\mathrm{Mg}$-carbonates may impede the preservation of biosignatures within these phases. Given the prevalence of morphologic biosignatures within aragonite samples and their absence within hydromagnesite, we recommend that aragonite should be a target sample for collection at Jezero Crater. [1] Horgan et al. (2020) Icarus 339, 113526. [2] Power et al. (2009) Chem. Geol. 260, 285-300. [3] Power et al. (2011) Geobiology 9, 180-195. [4] Balci et al. (2020) Geomicrobiol. J. 37, 401-425 [5] Águila et al. (2021) Eur. J. Phycol. 1-16. 